\title{
EMANCIPACIÓN, MERCADO HIPOTECARIO Y RESIDENCIAL
}

\author{
Anna García Masiá \\ Socióloga, Centre de Política del Sòl i Valoracions
}

Remisión Artículo: 21-5-2007

Palabras Clave: Emancipación, mercado hipotecario, mercado residencial, jóvenes.

\section{RESUMEN}

El artículo ${ }^{1}$ surge de la tesis en curso La emancipación de los jóvenes desde una perspectiva socioeconómica y del mercado inmobiliario. Propuestas de gestión social de la vivienda. Dicha tesis aborda el proceso de emancipación desde diferentes aspectos que lo favorecen y/o lo dificultan. La investigación parte de tres hipótesis referentes: a la situación socioeconómica de los jóvenes, al mercado residencial y a los efectos de la segunda transición demográfica, tanto a efectos estructurales como personales, que repercuten todos ellos en el retraso del proceso de emancipación y en las formas de convivencia y cohabitación.

El marco territorial del análisis es la Región Metropolitana de Barcelona, que ha experimentado un elevado crecimiento de los precios, que, a menudo ha provocado la emigración de la población de las grandes ciudades hacia otros municipios próximos en busca de una mejor calidad de vida y una vivienda más asequible. Aunque los estudios de casos se realizan en la comarca del Maresme debido al hecho que expresa con claridad este proceso descentralizador de las grandes ciudades hacia la periferia, como receptor de éste.

Se analiza, por un lado la situación socioeconómica de los jóvenes y los factores más determinantes en su proceso de emancipación, y por otro, la situación del mercado inmobiliario, así como los cambios que se han producido durante los últimos años. A su vez se contrasta y complementa mediante una encuesta ${ }^{2}$, que pone de manifiesto los aspectos más subjetivos del proceso, así como los factores subjetivamente más determinantes y la concreción de las necesidades. Necesidades materializadas en unos modelos y tipologías residenciales que, en última instancia se contrastan con el mercado residencial actual y el acceso de los jóvenes al mismo.

\section{JUVENTUD Y EMANCIPACIÓN}

La juventud es el período vital que se encuentra entre la vida infantil y la adulta, que responde a parámetros demográficos, pero también a la realidad y al reconocimiento social de su entorno. Pero el proceso de aprendizaje y de consolidación de los retos para pasar a la etapa adulta se ha prolongado, no solo por el incremento de los estudios, sino también por el aprendizaje y la formación en el mercado laboral, que se ha alargado igualmente. Con los contratos de prácticas, las becas de formación y los contratos temporales, entre otros, juntamente con la elevada competitividad laboral en los sectores más preparados, conseguir una estabilidad laboral y económica cada vez requiere más tiempo.

\footnotetext{
${ }^{1}$ Además, de presentarse dos comunicaciones en dos congresos, el IX Congreso Español de Sociología y la the 8th Annual Conference of the European Sociological Association.

${ }^{2}$ La encuesta se realiza en la comarca del Maresme con dos ámbitos de estudio: jóvenes emancipados/as y no emancipados/as, con cuotas de representación por municipios.
} 
Además, entrada la Segunda Transición Demográfica con la situación de precariedad tanto económica y laboral como personal, que caracteriza la sociedad post-industrial, pendiente de la satisfacción de la biografía personal e inmersa en un momento de cambios en la forma de cohabitación y de residencia, el período se alarga. Situaciones todas ellas que afectan al colectivo de jóvenes de diferente manera según su edad y características, para lo cual se analizan el conjunto de datos y situaciones en función de la consolidación del proceso de emancipación en relación con la edad: las personas jóvenes en edad de primera emancipación, aquellas de entre 15 y 24 años que, por su condición socioeconómica, laboral,... y por su edad se encuentra en una emancipación menos estable y precaria que el siguiente grupo, de 25 a 34 años, o en edad de formación de un hogar estable. Pues, en la segunda etapa, con los estudios normalmente terminados, se considera que las personas se encuentran en otro momento del ciclo vital, con una mayor estabilidad, económica, laboral, personal,... que les lleva a consolidar su hogar y, a menudo, a formar familia.

Los gráficos 1 y 2 son el reflejo de las diferencias entre ambos grupos en lo que se refiere a su situación laboral y su proceso de emancipación en los que, en ambos casos se aprecia un considerable retraso en el proceso de emancipación, con un menor porcentaje de jóvenes emancipados que en los años noventa y dos mil.

Gráfico 1. Evolución de los indicadores de actividad y de la tasa de emancipación de los jóvenes en edad de primera emancipación de Barcelona. 1985-2000 (\%) ${ }^{3}$

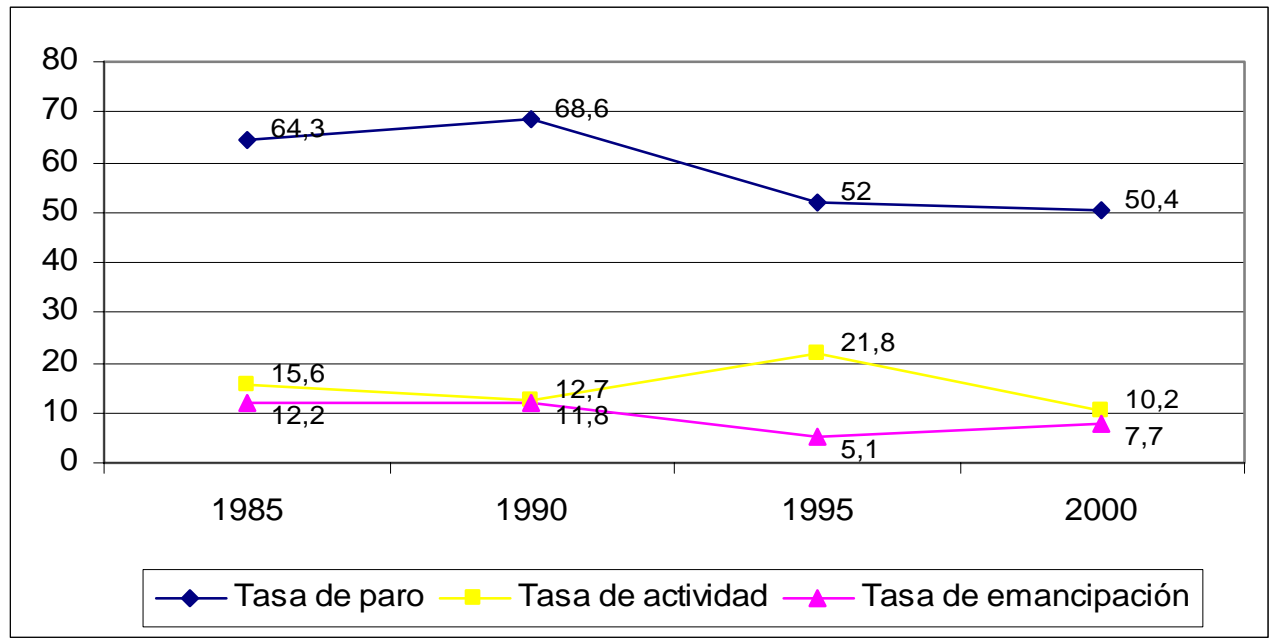

Fuente: Enquesta de les condicions de vida i hàbits de la població, 1985, 1990, 1995 y 2000 IERMB ${ }^{4}$.

Si bien es cierto que los miembros más jóvenes del primer grupo son bastante jóvenes para emanciparse e influencian en el peso relativo que tengan para el conjunto del grupo en el

\footnotetext{
${ }^{3}$ El grupo de jóvenes en edad de primera emancipación en este caso corresponde a los jóvenes de entre 18 y 24 años (y no de 15 a 24), aunque debido a la poca representatividad de emancipados de este grupo, la diferencia no es muy relevante. La tasa de emancipación de los jóvenes de la RMB en edad de primera emancipación calculada a partir de los datos del censo de 2001 del INE es del 8,9\%, y diverge en 1,2 puntos porcentuales de la calculada por el IERMB a partir de la encuesta de las condiciones de vida y hábitos de la población del 2000 para el grupo de jóvenes de entre 18 y 24 años. Dado que la diferencia es tan poco significativa, se consideraran los datos del IERMB por su referencia al ámbito territorial y su periodicidad, pues significativamente se refiere al mismo fenómeno social y familiar.

${ }^{4}$ Fuente: Miralles, C.; Donat, C.; Encinas, I. (2006): Característiques de l'oferta i la demanda d'habitatge a Barcelona en el context metropolità. (pág. 50) IERMB.
} 
mismo proceso, la reducción de la proporción de jóvenes emancipados desciende del 12\% en 1985 al 7,7\% el 2000. Además, la tasa de actividad se corresponde con una diferencia de aproximadamente 3 puntos porcentuales por encima de la tasa de emancipación en todos los quinquenios, con una reducción en el conjunto del período, a excepción de 1995, cuando la evolución es inversa, en favor de la actividad y en detrimento de la emancipación; pues se debe al alargamiento del período de formación y del retraso en la incorporación al mercado laboral, que se traduce en un alargamiento del período de inactividad, una reducción de la tasa de paro y una emancipación más tardía.

Gráfico 2. Evolución de los indicadores de actividad y de la tasa de emancipación de los jóvenes en edad de emancipación estable de Barcelona. 1985-2000 (\%)

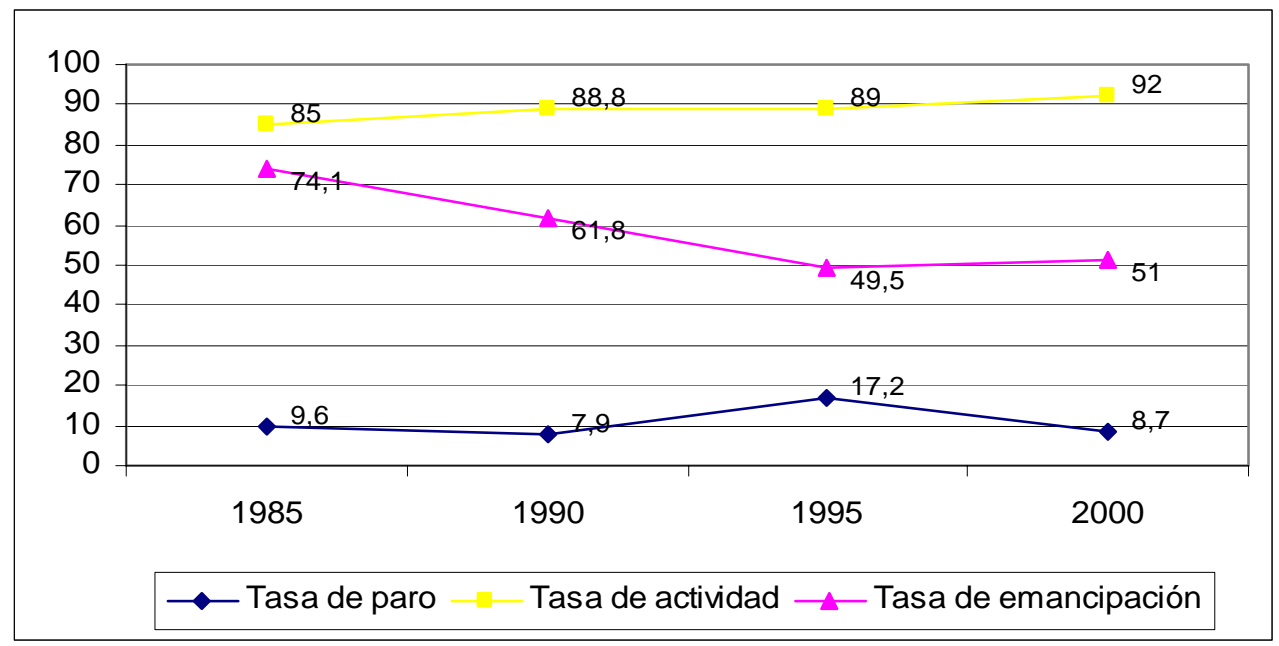

Fuente: Enquesta de les condicions de vida i hàbits de la població, 1985, 1990, 1995 y 2000 IERMB ${ }^{5}$.

El segundo grupo, en cambio, al acercarse a la edad adulta, se emancipa en una mayor proporción. Aunque igualmente se aprecia una reducción de la tasa de emancipación, pues en 1985 tres cuartas partes de los jóvenes de dicho grupo estaban emancipados, mientras al final del período, en el 2000, sólo lo están la mitad. Reducción que contrasta con el progresivo incremento de la tasa de actividad, que incrementa del $85 \%$ al $92 \%$, y con una reducida tasa de paro inferior al 10\% (a excepción de 1995 que llega al 17\%).

Así como el grupo de jóvenes de menor edad tiene una tasa de emancipación muy próxima a la tasa de actividad y muestra una evolución prácticamente paralela, aunque con un retraso de la emancipación respecto el comportamiento de la actividad, ya que actúa en función del mercado laboral y la mayoría de la población activa de este grupo es la misma que la emancipada; en el caso de los jóvenes de mayor edad la distancia entre la actividad y el paro se maximiza a lo largo del periodo. Así pues, si los jóvenes en edad de emancipación estable, retrasan su proceso de emancipación y reducen su tasa, y no es debido al alargamiento del periodo formativo ni al retraso en la incorporación al mercado laboral (pues, en el 2000 el 92\% de la población de este grupo de edad es activa y solo un $8,7 \%$ está en paro), hay que buscar los motivos de la reducción en la emancipación en otros factores.

El proceso de emancipación, ha cambiado, también se ha flexibilizado y diversificado. Deviene un cambio más en la vida que, respondiendo a la flexibilidad de la sociedad actual, pudiendo ser definitivo o no y llevándose a cabo con una o más personas a pesar de no tener un carácter

\footnotetext{
${ }^{5}$ Ibídem.
} 
definitivo y perdurable. Ahora bien, a estos cambios hay que añadirle un parque de viviendas adecuadas a los mismos, viviendas temporales, cambiantes, con variedad de precios, tamaño, distribución y tenencia con tal que la población que no establece lazos definitivos y perdurables (ya sea con personas o con la vivienda en sí) encuentre viviendas que satisfagan sus necesidades.

Otro de los factores que influencian el proceso de emancipación, más allá de la tasa de actividad, es la calidad de ésta, el tipo de contrato, la duración y el nivel de ingresos. Teniendo en cuenta la elevada temporalidad de los contratos laborales entre las personas jóvenes (el $59 \%$ de los contratos laborales de jóvenes catalanes menores de 25 años son temporales) y la inferioridad en el nivel de ingresos, por debajo de la media, junto a la evolución del precio de la vivienda, no es de extrañar que se reduzca la tasa de emancipación.

Gráfico 3. Porcentaje de ingresos medios por grupos de edad respecto el total 1995, 2002

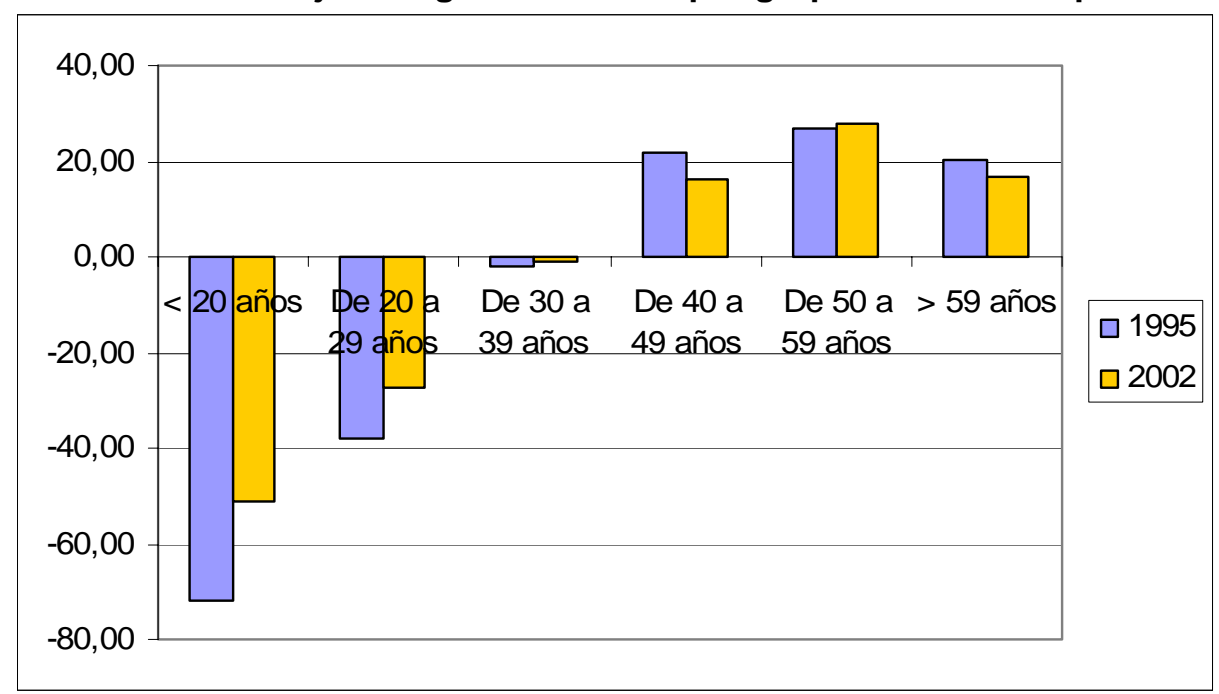

Fuente: INE, datos de la EPA. Elaboración propia

Tal como muestra el gráfico 3 , no es hasta la treintena que se percibe un nivel de ingresos medios; hasta dicha edad, los ingresos son de entre un 27 y un $51 \%$ inferior a la media; mientras el nivel de ingresos más elevado se percibe alrededor de la cincuentena. Pero, si al nivel de ingresos se añade el precio de la vivienda, que entre 1991 y 2004 ha incrementado en un $195 \%$, se entiende parte de la problemática.

\section{EL MERCADO HIPOTECARIO VS MERCADO RESIDENCIAL}

El mercado inmobiliario actual parece olvidar el articulo 47 de la Constitución Española (por el que todas las personas españolas tienen derecho a una vivienda digna y adecuada), puesto que las instituciones públicas, lejos de crear y promover un parque público de vivienda, han permitido al mercado actual actuar libremente con la vivienda mediante unas políticas legislativas y fiscales que han favorecido la propiedad en detrimento del alquiler; convirtiendo un derecho básico como la vivienda en una mercancía, valorada más por su valor de cambio que por su valor de uso. 
No es de extrañar pues que, ante la rigidez del mercado inmobiliario actual, con un $79 \%$ de las viviendas de propiedad y tan solo el $18 \%$ de alquiler ${ }^{6}$ y con un triste $8 \%{ }^{7}$ de las viviendas protegidas; y ante una reiterada bajada de los tipos de interés de las hipotecas y una creciente inversión en el mercado inmobiliario, se haya reforzado la imagen de la vivienda como un bien de inversión que ha llevado hasta a los sectores más vulnerables a participar de este ejercicio de inversión provocando endeudamientos que comprenden la totalidad de la vida laboral, olvidando los ciclos económicos y las subidas y bajadas de precios y pensando más en la rentabilidad económica del inmueble que en la calidad de vida cotidiana.

La participación en la inversión inmobiliaria a título particular no es gratuita pues, la dependencia hacia el mercado hipotecario crea situaciones de riesgo ante las variaciones de los tipos de interés o de las situaciones personales, socioeconómicas y laborales, presentes y futuras; que, ante la expectativa de mejora a menudo se considera por encima de las capacidades.

Para comprender el esfuerzo económico de los hogares jóvenes en su acceso a la vivienda hay que tener en cuenta que la situación económica de las persones jóvenes se caracteriza por una mayor precariedad respecto la del conjunto de la población y que el nivel de ingresos de los hogares jóvenes es inferior a la media. Además, la situación hipotecaria actual mantiene el tipo de interés bajo (un 3,28\% en el 2005), aunque ha incrementado en estos dos últimos años, y, para paliar el efecto de éste en las nuevas hipotecas, se ha incrementado el plazo de retorno hasta los 50 años. Siendo lo realmente significativo el esfuerzo económico que supone el coste de la vivienda en relación a los ingresos y manteniendo el incremento de los ingresos y de los precios de las viviendas que se han producido durante los últimos quince años, los hogares jóvenes tienen que destinar una media del $52,8 \%{ }^{8}$ de sus ingresos al pago de la hipoteca.

\section{Gráfico 4. Esfuerzo económico (\%) y duración del préstamo para el pago de la hipoteca de los hogares jóvenes}

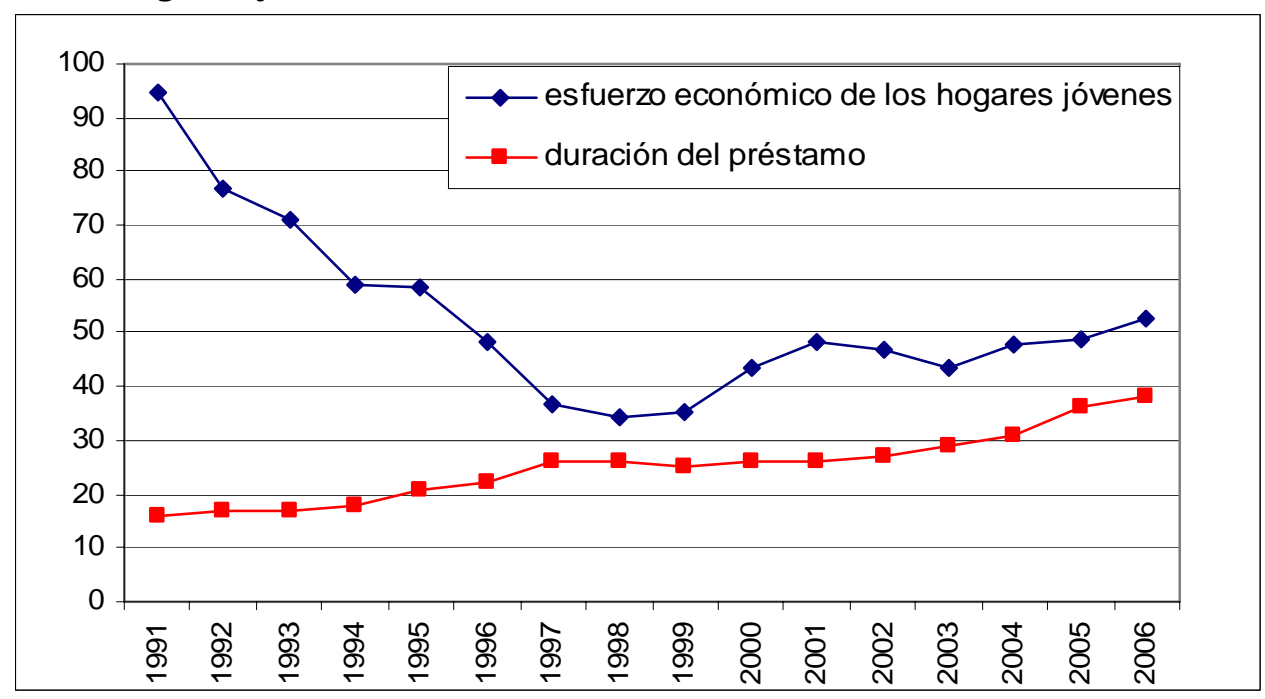

Fuente: INE. Banco de España. Ministerio de la Vivienda. Elaboración propia

\footnotetext{
${ }^{6}$ Datos de la RMB: elaboración propia a partir de los datos del censo de 2001.

${ }^{7}$ Datos de la RMB: elaboración propia a partir de los datos de viviendas acabadas 2000-2005 de la Generalitat de Catalunya.

${ }^{8}$ Elaboración propia, cálculo realizado a partir de los datos del Banco de España, el Ministerio de la Vivienda, el INE y la publicación Els joves catalans i l'habitatge 1999-2003.
} 
Éste esfuerzo económico ha variado durante los últimos años en función de los ingresos de los hogares y la duración y el tipo de interés del crédito. Cuanto más largo es el período de retorno del mismo menor es el esfuerzo económico que tienen que hacer los hogares.

Durante el primer quinquenio de los noventa y hasta 1997 el esfuerzo económico fue muy elevado debido al elevado tipo de interés (superior al 9\%) y a la reducida duración del período de retorno del mismo (con un máximo de poco más de 20 años), pero a medida que se ha reducido el tipo de interés (sobretodo a partir de 1995) se ha reducido igualmente el esfuerzo económico, con un descenso prolongado hasta 1997, cuando se produce un incremento del precio de la vivienda sin fin hasta el último año analizado. Incremento de precios que sólo ha logrado mantener el esfuerzo económico entre el 35 y el 52\% gracias a la reducción del tipo de interés y al incremento del plazo de retorno, pues el mercado hipotecario es el que permite el acceso de les jóvenes al mercado residencial a pesar del incremento de los precios de las viviendas.

\section{Gráfico 5. Duración y tipo de interés de las hipotecas}

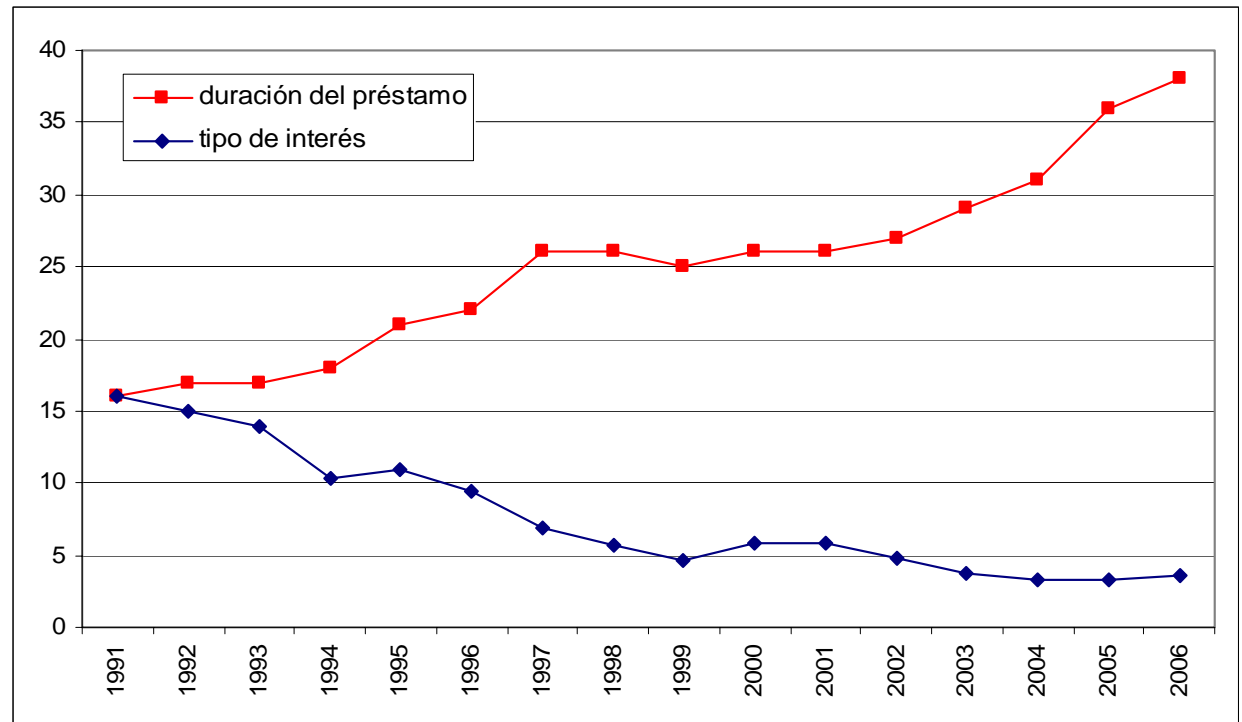

Fuente: INE. Banco de España. Ministerio de la Vivienda. Elaboración propia

Tal como muestra el gráfico 5, inversamente proporcional a la reducción del tipo de interés, incrementa el término de pago del préstamo.

Para hacer frente al pago de las viviendas en constante crecimiento exponencial de los precios, la oferta hipotecaria de los bancos y cajas de ahorros han propuesto nuevas fórmulas hipotecarias con tipos de interés bajos pero variables e incrementando el término del pago del mismo.

Se crea así un elevado diferencial entre el valor de las viviendas y la capacidad de pago de las mismas por parte de los hogares que ha provocado una falsa imagen de negocio a través del mercado inmobiliario, reforzada por los bajos tipos de interés de las hipotecas. Condicionando la calidad de vida de la población hipotecada a la evolución de los tipos de interés y a la revalorización de la vivienda usada. 


\section{Gráfico 6. Modelo explicativo del esfuerzo económico}

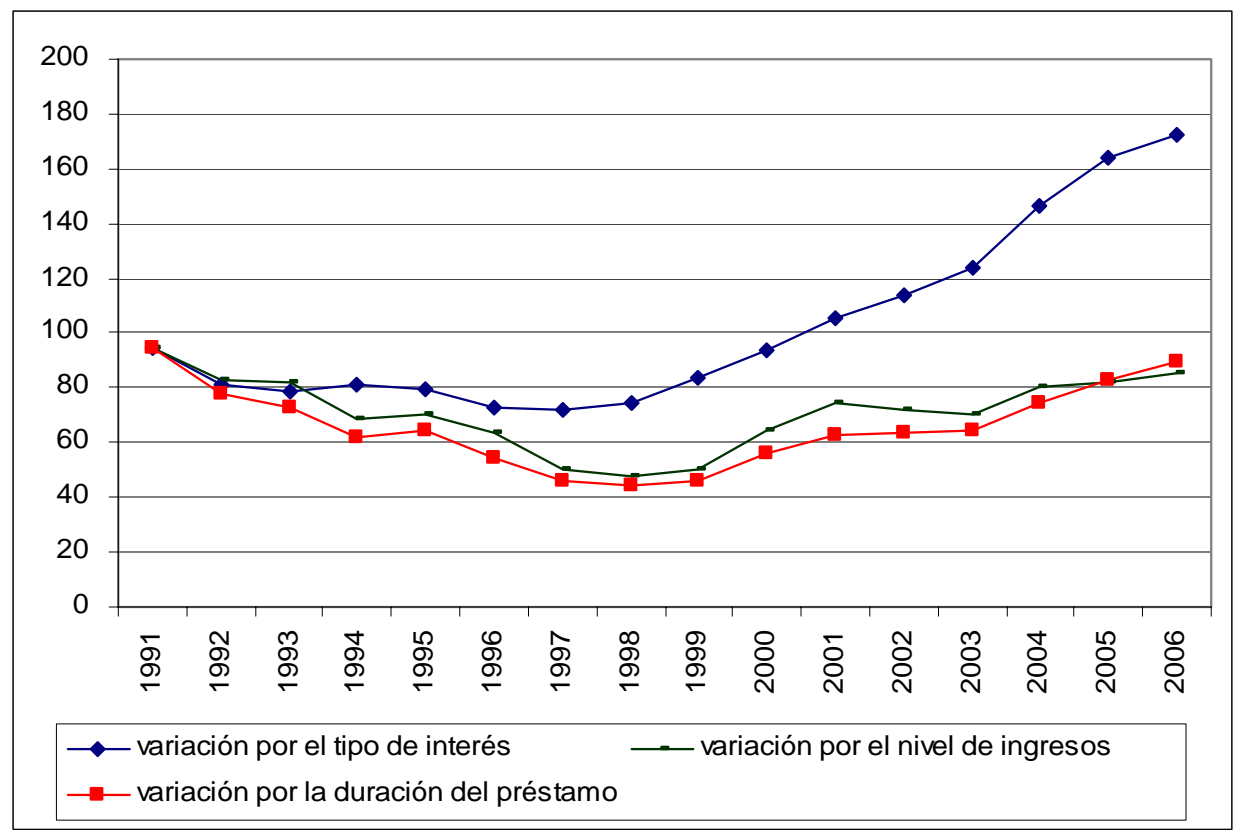

Fuente: INE. Banco de España. Ministerio de la Vivienda. Elaboración propia

Con tal de predecir situaciones futuras e identificar el factor más relevante en el esfuerzo económico de los hogares, se crea el modelo explicativo del esfuerzo económico en el que se analiza la situación de este período manteniendo cada uno de los factores que lo condicionan. Así, si se hubiera mantenido el tipo de interés de 1991 durante todo el período, el esfuerzo económico que tienen que hacer los hogares jóvenes, que ya en un primer momento era muy elevado (casi el $100 \%$ de los ingresos medios de los hogares destinados al pago de la hipoteca), incrementa hasta casi duplicarse (175\%).

A pesar que el nivel de ingresos y la duración del préstamo también influyen en el esfuerzo económico, el mantenimiento de cada una de las variables hace variar de forma diferente el esfuerzo económico, reduciéndose entre 1996 y 1999 e incrementando de nuevo hasta porcentajes de entre el 85 y el $90 \%$, pero son menos influyentes que el tipo de interés. Hay que tener presente, que el factor más determinante del esfuerzo económico para el pago de la hipoteca es el tipo de interés y que si éste incrementa los hogares con el pago de la hipoteca pendiente cada vez tendrán que hacer un esfuerzo económico más elevado para paliar este gasto.

\section{PROCESO DE EMANCIPACIÓN VS MERCADO RESIDENCIAL}

Para explicar la variación en la tasa de emancipación para ambos grupos de jóvenes (en edad de primera emancipación y en edad de emancipación estable), se han utilizado variables de diversa índole ${ }^{9}$, llegando a la conclusión que los factores más significativamente correlacionados con la tasa de emancipación, para ambos grupos son los relacionados con el

\footnotetext{
${ }^{9}$ Se han utilizado variables económicas y laborales como: la tasa de ocupación, la temporalidad de los contratos laborales, la edad de primonupcialidad y las variables que comprenden ambos grupos: ingresos medios de los hogares jóvenes, esfuerzo económico para el pago de la hipoteca, precio de la vivienda y esfuerzo económico en años de dedicación del salario íntegro para el pago de la vivienda.
} 
mercado laboral: la tasa de ocupación y la estabilidad laboral, seguidas del precio de la vivienda y el esfuerzo económico en años de dedicación íntegra de los ingresos anuales para el pago de la misma.

Gráfico 7 y Gráfico 8. Regresiones lineales de las variables de ocupación y temporalidad respecto la emancipación para el grupo de jóvenes de 15 a 24 años
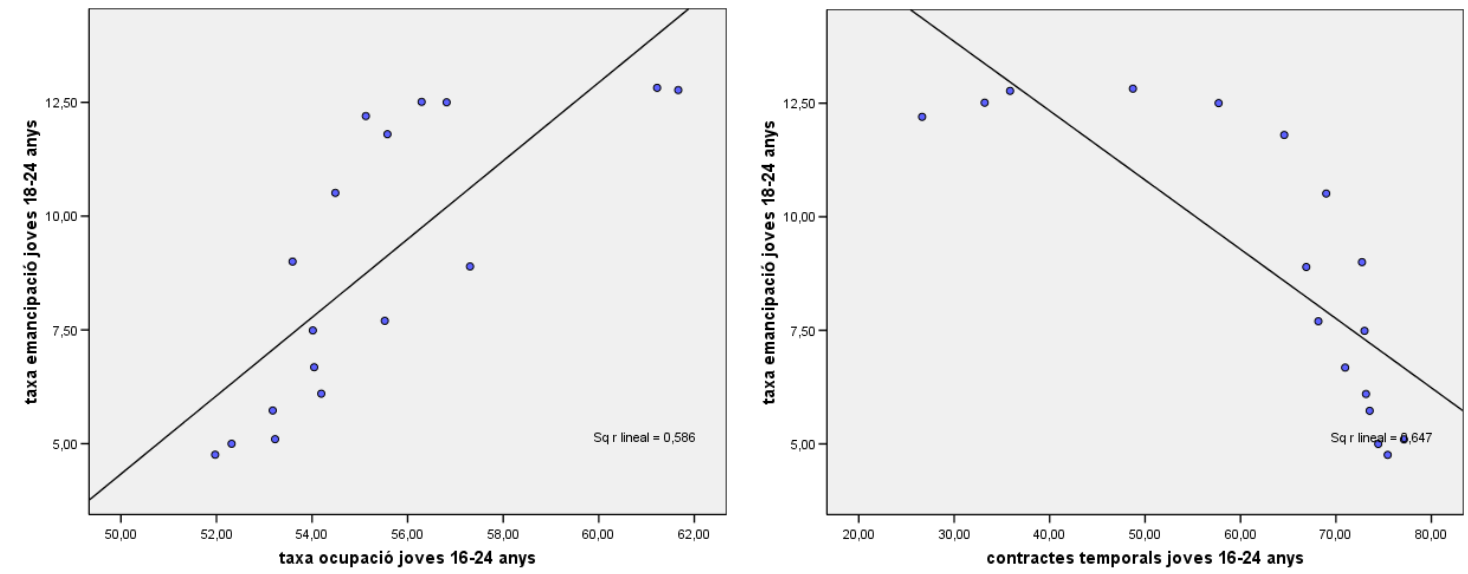

Fuente: INE, datos de la EPA, Enquesta de les condicions de vida i hàbits de la població, 1985, 1990, 1995 i 2000 IERMB, Trilla, C. (2004). Elaboración propia

Aunque el precio y el esfuerzo económico en años están altamente correlacionados con la temporalidad de los contratos laborales y en menor medida con la tasa de ocupación, éstas últimas están correlacionadas con la tasa de emancipación.

Gráfico 9 y Gráfico 10. Regresiones lineales de las variables de ocupación y temporalidad respecto la emancipación para el grupo de jóvenes de 25 a 34 años
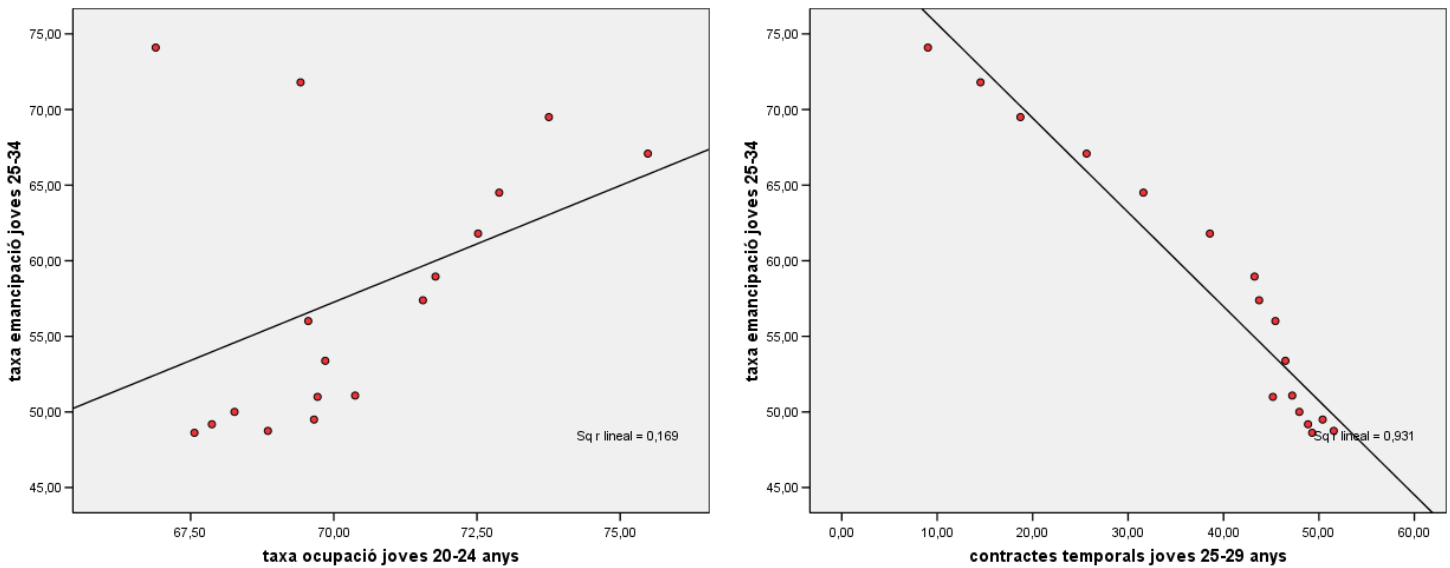

Fuente: INE, datos de la EPA, Enquesta de les condicions de vida i hàbits de la població, 1985, 1990, 1995 i 2000 IERMB, Trilla, C. (2004). Elaboración propia.

Para el grupo de mayor edad la predicción es más exacta, las variables de ocupación y temporalidad de los contratos laborales están correlacionadas con la tasa de emancipación. Así, la emancipación depende de la ocupación, pero también de la estabilidad de ésta, pues en caso contrario (temporalidad) está relacionada negativamente con más intensidad. 
Una vez analizados los determinantes de la emancipación a partir de datos cuantitativos, hay que analizar los provenientes de la encuesta, donde no sólo se hace referencia a datos cuantitativos, sino que también se tienen en cuenta las opiniones y las percepciones subjetivas.

Se trata de 400 encuestas telefónicas realizadas en abril de 2007 en la comarca del Maresme, 315 a jóvenes emancipados/as y 95 a jóvenes no emancipados/as que manifestaron tener intención de hacerlo en los próximos dos años, con cuotas de representación por municipios. En una primera explotación de los datos de las encuestas por grupos de edad, se aprecian diferencias entre grupos de edad y entre ambos universos.

Una primera muestra de la dificultad en el proceso de emancipación es la mayor voluntad de emancipación de las personas que no lo están (un 65\% querría emanciparse inmediatamente) frente a la voluntad de haberlo hecho con anterioridad en el caso de la población emancipada encuestada (el 33\% querría haberlo hecho con anterioridad). Esta voluntad incrementa con la edad, sobretodo si se tiene en cuenta como una posible demanda de vivienda inmediata la proporción de ésta que ha buscado piso, pues sólo el 39\% de los jóvenes no emancipados que querrían hacerlo de inmediato han buscado piso (lo cual representa el $25 \%$ del total). Por otro lado, casi la mitad de los que quieren vivir en el mismo municipio de residencia cree que no será posible debido al elevado precio de la vivienda.

La realidad, demuestra que, a pesar de las optimistas expectativas de las personas jóvenes, aquellas que todavía no se han emancipado tienen una visión más negativa que aquellas que sí lo han hecho, tanto en lo que se refiere a dificultades como en lo que se refiere a pagos. Cuanto más joven es la persona encuestada, mayor es la variedad de opciones de convivencia, mientras las personas de más edad vivirían con amigos/as en menor proporción, las personas no emancipadas vivirían en mayor proporción con amistades que las que están emancipadas; pero en lo que se refiere a la vivienda, se aprecia una mayor disposición al alquiler por parte de las personas no emancipadas de la realidad de las que sí lo están, además esta predisposición incrementa a partir de los 25 años, mientras la realidad demuestra valores inferiores.

La población joven no emancipada, que sirve a modo de la posible futura demanda de viviendas tiene una visión de la emancipación y la vivienda bastante similar a la realidad de sus coetáneos emancipados, aunque difieren en la consideración de la realidad como más negativa de lo que resulta ser en realidad, a menudo influenciada por los medios de comunicación y por la visión subjetiva del proceso de emancipación. Así, contrariamente a sus coetáneos emancipados, cuanto mayor es la persona no emancipada encuestada, más dificultad cree que tendrá en el pago de la hipoteca, considerando el precio de la vivienda como el motivo principal de la no adecuación de ésta a sus necesidades. En lo referente a las consideraciones respecto al trabajo, los estudios,... el factor que consideran más importante es el trabajo y esperan tener un contrato indefinido en un $78 \%$ de los casos, lo cual demuestra la correlación entre ocupación estable y emancipación, pues tienen expectativas de mejora para el momento de la emancipación.

En cambio, la población emancipada, al haber pasado por todo el proceso de emancipación, con una visión más real de la situación, se habría emancipado antes de lo que lo hizo en los grupos de mayor edad y no lo hizo por motivos económicos, seguidos de los estudios y los laborales. Pero además, en el proceso de consolidación de la emancipación y la vida propia, se aprecia una mejora tanto en el nivel de estudios como en el nivel profesional, contractual y económico entre el momento en que se emancipó y actualmente. Lo cual pone de manifiesto que, si bien es necesaria una cierta estabilidad laboral y económica, no es imprescindible para emanciparse, pues con el tiempo se consolida para mejorar.

La vivienda joven se caracteriza por una menor proporción de propiedad que la media, con un $70 \%$, mientras el $24 \%$ de las viviendas son de alquiler, siendo los grupos de menor edad los 
que viven en mayor proporción en viviendas de alquiler; aunque la primera resulta menos cómoda y permisible que la segunda, especialmente en los grupos de menor edad; pues mientras el 39\% de las personas jóvenes emancipadas que viven en propiedad consideran que la cuota mensual no les resulta cómoda, en el caso del alquiler desciende al $25 \%$. Por lo tanto, el alquiler puede ser una solución ante la dificultad de acceso al mercado inmobiliario, pues no solo permite mayor movilidad residencial con menos dificultades que la propiedad, sino que además, tiene un coste personal y subjetivo inferior, a menudo también porque el alquiler se piensa de forma temporal, valorando las necesidades presentes, y la propiedad, al ser más rígida se piensa para un futuro que todavía está por llegar, costeando así mayores costes de los necesarios en el presente. El hecho que tan solo el 36,5\% de los hogares jóvenes consideren su vivienda para el futuro, a pesar que la voluntad asciende hasta el $86 \%$, pone de manifiesto esta visión de rigidez y perdurabilidad de los inmuebles.

\section{CONCLUSIONES}

En esta primera explotación de la encuesta se corroboran algunas de las hipótesis planteadas que, en posteriores análisis en profundidad habrá que analizar con mayor detalle. Se aprecia una visión de la realidad del mercado inmobiliario por parte de las personas jóvenes no emancipadas muy próximo a la realidad, aunque con una visión más negativa del proceso de emancipación de la que tienen sus coetáneos emancipados. Pero, a diferencia de lo que podría esperarse, están más dispuestos a residir en viviendas protegidas, de propiedad y de alquiler, y en diferentes situaciones, con menos prejuicios y exigencias de lo que a menudo se les atribuye.

En cuanto a las características de la vivienda, a pesar del deseo de perdurabilidad y estabilidad, la mayoría de éstas responden a las necesidades presentes; lo cual pone de manifiesto la dificultad en el proceso de emancipación y en el pago del coste de la vivienda y además contrasta con la todavía predominante voluntad de propiedad por encima del alquiler. Influenciada por la imagen social del mercado inmobiliario que valora las viviendas por su mercantilización, que hace de la propiedad un valor en sí mismo hasta el extremo de destinar más de la mitad de los ingresos al pago de la hipoteca, incrementando el periodo de retorno de la misma hasta los 40 y 50 años, y en con un actual incremento del tipo de interés que puede hacer peligrar la calidad de vida hasta la insostenibilidad.

La imposibilidad del mercado inmobiliario para resolver por sí mismo las necesidades residenciales de los segmentos más desfavorecidos de los jóvenes, juntamente con la reciente y cada vez mayor voluntad ciudadana por solucionar dicha dificultad, requiere acciones para regular el mercado inmobiliario, o para a atender estas ineficiencias mediante una política de vivienda, urbanística, fiscal, etc. atenta a estas carencias. En este contexto, hay que extender el estudio al ámbito político, económico y legislativo para lograr una visión más general, comprender los nuevos instrumentos que se disponen y las formas de aplicación de soluciones viables tanto para la situación actual como para la que se está gestando con el reciente incremento del tipo de interés hipotecario.

Paralelamente, a la actuación en materia de política de vivienda, urbanística, fiscal, ... hay que incidir en el imaginario social que se ha creado alrededor del mercado inmobiliario en tanto que generador de rendas y actuar en beneficio del valor de uno del mismo. Los recientes movimientos sociales en defensa de una vivienda digna, en cualquiera de las formas que abastan ayudan a la resocialización y revalorización del mercado inmobiliario en sus orígenes y según sus virtudes y características.

Los municipios toman una especial relevancia, pues deben servirse de la legislación urbanística para incrementar el patrimonio público del suelo a través de las reservas del $20 \%$ 
del techo destinado a uso residencial de los Planes de Ordenación Urbanística Municipal aprobados con posterioridad a la nueva legislación ${ }^{10}$ y la reserva obligada de un mínimo del $10 \%$ del techo destinado a uso residencial de nueva implantación en los municipios de más de 10.000 habitantes y las capitales de comarca. Pudiendo servirse además, del $5 \%$ del suelo destinado a equipamientos para la construcción de viviendas dotacionales. Aún así, mientras no se determinen de forma más concreta y rígida los posibles destinos del patrimonio público del suelo vivienda no se avanzará; medidas como las que propone el Projecte de Llei pel Dret a l'Habitatge, con censuras y represalias para aquellos propietarios que no cumplan con su función social de la propiedad serán de gran ayuda en el momento en que se aprueben.

Hace falta pues, considerar otros regímenes de tenencia y gestionar la vivienda pública ${ }^{11}$ mediante formas de gestión intermedias entre las tradicionales de tenencia, la compra y el alquiler, intervenidas por la administración o alguna entidad gestora que actúe en beneficio social y no solo mercantil. Con el que es pueden controlar las ventas de inmuebles con un sobreprecio oculto y las segundas transmisiones que se producen después de los términos de preservación establecidos legalmente.

La primera medida histórica de control de estos comportamientos fraudulentos que se producen en las transmisiones de los inmuebles es el alquiler público, aun cuando comporta otros inconvenientes como el gasto público que genera y el estado de conservación de los parques de alquiler públicos. Es por este motivo que se proponen nuevas fórmulas más imaginativas y flexibles, a menudo intermedias entre la entidad pública y el propietario y entre la compra y el alquiler tales cómo: el derecho de superficie, la promoción de viviendas con venta a carta de gracia, el alquiler con opción de compra, el alquiler protegido o intervenido por el diferencial de renta o la titularidad compartida público-privada de las viviendas.

Finalmente, las cooperativas de viviendas o las de cesión de uso, así como la rehabilitación y reconversión de usos en espacios públicos y privados permite nuevas fórmulas que, combinadas con las anteriores facilitan el acceso a la vivienda así como la flexibilidad y la variedad en sus usos, destinos y períodos. Medidas que pueden tomar forma mediante la LLei de Barris que, además de ser una transformación urbana de los núcleos antiguos de los cascos urbanos reformándolos, transformándolos y adaptándolos a las necesidades del barrio en la actualidad, permite la construcción y rehabilitación de edificios, así como la conversión de usos de los mismos para hacerlos habitables. Con la posibilidad de gestionarse mediante cualquiera de estas fórmulas que permiten un uso más social.

Al fin y al cabo configuran un conjunto de fórmulas de propiedad, de gestión, y de tenencia más flexibles que el régimen tradicional de propiedad o alquiler. Fórmulas en las cuales interviene la administración o alguna entidad gestora que actúa en beneficio colectivo y no sólo mercantil. Así, se pueden hacer viviendas que respondan a las necesidades de la población como una verdadera alternativa económicamente viable, permitiendo a la población joven acceder a viviendas que reúnan las características de requieren, transformando el mercado inmobiliario en un mercado más amplio con diversidad de regímenes de tenencia y de fórmulas y soluciones, con un parque público de viviendas paralelo al privado que ejerzan un verdadero control del precio de la vivienda y que permita a las personas jóvenes y las que lo requieran cambiar de vivienda con mayor facilidad, cumpliendo así con el mandato del artículo 47 de la constitución española.

\footnotetext{
${ }^{10}$ Llei $10 / 2004$

${ }^{11}$ Clavell, D. (2003) Instruments urbanístics per a una política de sòl i habitatge a Catalunya Qüestions d'habitatge 11. Barcelona Patronat Municipal de l'Habitatge de Barcelona. Ajuntament de Barcelona.

Clavell, D.; Trilla C. (2004) Propostes alternatives de promoció per a una nova orientació de l'oferta d'habitatge protegit de la societat urbanística metropolitana de rehabilitació i gestió, S.A. REGESA Qüestions d'habitatge 12. Barcelona Patronat Municipal de l'Habitatge de Barcelona. Ajuntament de Barcelona.
} 


\section{BIBLIOGRAFÍA}

Bosch, J.; Gibarja, O. (2003). L'Habitatge a Catalunya en l'àmbit local: diagnosi, propostes $i$ solucions a un problema creixent Barcelona, Fundació Carles Pi i Sunyer d'Estudis Autonòmics i Locals.

Capel, H. (2005) El modelo Barcelona: Un examen crítico. Ediciones Del Serbal, Barcelona.

Carceller, X.; Pérez, C. (1995) Legislació urbanística a Catalunya curs bàsic 3a edició, Barcelona, UPC.

Casals, J; Garcia, M.; Merino, R.; Quesada, M. (2004) Enquesta als joves de Catalunya 2002 col.lecció estudis 13, Barcelona, Secretaria General de la Joventut.

Chueca Goitia, F. (1980) La ciutat com a realitat històrica, no és mai independent de les etapes per les quals ha passat en la seva evolució: és actualització d'elles i la seva projecció cap a l'avenir. Breve historia del urbanismo. Madrid: Alianza Editorial.

Clavell, D. (2003) Instruments urbanístics per a una política de sòl i habitatge a Catalunya Qüestions d'habitatge 11. Barcelona Patronat Municipal de l'Habitatge de Barcelona. Ajuntament de Barcelona.

Clavell, D.; Trilla C. (2004) Propostes alternatives de promoció per a una nova orientació de l'oferta d'habitatge protegit de la societat urbanística metropolitana de rehabilitació i gestió, S.A. REGESA Qüestions d'habitatge 12. Barcelona Patronat Municipal de l'Habitatge de Barcelona. Ajuntament de Barcelona.

Coll, J.I.; Guarner, V.; Hosta, LI. (1992) La Pràctica de la gestió urbanística Barcelona, Generalitat de Catalunya. Departament de Política Territorial i O.P. Direcció General d'Urbanisme.

Cortés, L (2002) Ciudad, vivienda y ciudadanía. Modelos de desarrollo urbano / modelos de ciudad. La ciudad como un organismo sujeto a procesos constantes de transformación. 25 de Junio de 2002

Garcia, P.; Garcia, A.; Fullaondo, A. (2005) Problemàtica de l'habitatge dels joves a Catalunya. Barcelona Centre de Política del Sòl i Valoracions de la UPC.

Garcia, P.; Renau, A. (1993) L'emigració de Barcelona: causes i característiques. El mercat de I'habitatge com a factor incentivador de l'emigració. Barcelona Centre de Política del Sòl i Valoracions de la UPC.

Generalitat de Catalunya (2004) Informe sobre el sector de l'habitatge a Catalunya 2004. Generalitat de Catalunya. Departament de Medi Ambient i Habitatge. Direcció General d'Habitatge.

Mancomunitat de Municipis de I'Àrea Metropolitana de Barcelona; Iglesias, A.; Vendrell, J. (2003) Habitatge protegit metropolità: 1995-2003 Barcelona, Mancomunitat de Municipis de l'Àrea Metropolitana de Barcelona.

Miret, P. (2004) Emancipació domiciliària, laboral i familiar dels joves de Catalunya col.lecció aportacions 25, Barcelona, Secretaria General de la Joventut.

Trilla, C.; Institut DEP (2000) Els joves catalans i l'habitatge col-lecció estudis 3, Barcelona, Secretaria General de la Joventut.

Trilla, C.; DEP Consultoria Estratègica (2004) Els joves catalans i l'habitatge 1999-2003 col-lecció estudis 12, Barcelona, Secretaria General de la Joventut 